\title{
Experimental Study on Formation Slip under Injection- Production Interregional Pressure Difference Based on the Abnormal Similarity Theory
}

\author{
Chaoyang Hu $\mathbb{D}^{1}{ }^{1}$ Fengjiao Wang $\mathbb{D}^{1},{ }^{1}$ Tingting Wang $\mathbb{D}^{2},{ }^{2} \mathrm{Chi} \mathrm{Ai}^{1}{ }^{1}$ and Chenyu $\mathrm{Wu}^{3,4}$ \\ ${ }^{1}$ Laboratory of Enhanced Oil Recovery of Education Ministry, Northeast Petroleum University, Daqing, 163318 Heilongjiang, China \\ ${ }^{2}$ School of Electrical Engineering and Information, Northeast Petroleum University, Daqing, 163318 Heilongjiang, China \\ ${ }^{3}$ Daqing Oilfield Production Engineering Research Institute, Daqing, 163453 Heilongjiang, China \\ ${ }^{4}$ Heilongjiang Provincial Key Laboratory of Oil and Gas Reservoir Stimulation, Daqing, 163453 Heilongjiang, China
}

Correspondence should be addressed to Fengjiao Wang; wangfengjiao8699@126.com

and Tingting Wang; wangtingting@nepu.edu.cn

Received 18 February 2021; Accepted 11 August 2021; Published 7 September 2021

Academic Editor: Jia Liu

Copyright (C) 2021 Chaoyang Hu et al. This is an open access article distributed under the Creative Commons Attribution License, which permits unrestricted use, distribution, and reproduction in any medium, provided the original work is properly cited.

In oilfield development, the pore pressure difference between adjacent areas leads to cracks and slipping in the weak structural surface layer, which triggers the shear failure of the casing. The formation slip involves a large range of formation, and its amount is not proportional to the size of the slipping rock mass, which conventional physical models cannot simulate. In this study, based on the abnormal similarity theory, we derived the similarity coefficients of mechanical parameters with different horizontal and vertical proportions. Furthermore, an experimental device for simulating the formation crack and slip under interregional formation pressure difference was developed. Through the experiments, we obtained slip conditions under different pressure differences between adjacent areas and different oil layers and fault surface depths. The study shows that the pore pressure difference between adjacent areas is the driving force of the formation slips. The slip zone is located in the middle of two abnormal pressure zones, and the distance between the adjacent areas can affect the slip range. The deep burial of the oil layer and shallow depth of the weak structural surface can trigger a more significant formation slip. The experimental method proposed in this paper provides an experimental device and method for understanding the formation of cracks and slips on weak structural surfaces. The experimental results provide a theoretical basis for the prevention of shear-type casing damage caused by formation slip.

\section{Introduction}

When an oil field is developed, the average formation pressure difference between adjacent blocks gradually occurs, which leads to a formation pressure difference between adjacent areas. The pressure difference between adjacent areas can make the formation produce nonuniform longitudinal deformation and exert a force on the upper formation. For formations with weak upper horizontal structural surfaces, the pressure difference between the adjacent areas can lead to the formation of cracks and slips at the weak horizontal structural surfaces, leading to shear-type casing damage. Taking the Daqing Oilfield in China as an example, at the bottom of the Nen'er member in the upper oil layers, there is a mud-shale standard layer, which can be used as a standard for identifying other layers because of its obvious logging characteristics. This mud-shale standard layer has a small dip angle and a stable distribution throughout the entire region. There are a large number of low-strength fossils in the standard layer, which constitute the horizontal weak structural surface, and have been damaged in a large area, forming a horizontal crack surface. For example, after long-term high-pressure water injection and polymer injection development in the Daqing Oilfield, the Sazhong Development Zone has formed nine casing-damage concentration areas with a total area of $38.34 \mathrm{~km}^{2}$. The casing damage rate 
in the concentration area is as high as $80 \%$, and most are shear-type casing damage [1-4]. The casing damage in these areas has the characteristics of layer concentration, region concentration, and time concentration.

Domestic and foreign scholars have studied the mechanism of casing damage for many years, and both have confirmed that the change in reservoir injection and production pressure can cause the crack and slip of the horizontal weak structural surface [5-8]. At present, the typical research method is to use a finite element model and simulations to determine the influence of reservoir deformation on the degree of cracks, slips, and casing damage [9-11]. However, with the long-term overpressure development of oil fields, casing damage is increasingly frequent, and even regional casing damage is formed in the standard mud-shale formations of the Daqing Oilfield [12-14]. Because the mechanism of slip casing damage on the mud-shale crack surface is still not clear, and the mechanical model of formation slip and experimental methods have not been formulated, only field experience or conservative methods can be generally used for prevention measures at present. Additionally, a large area of injection reduction and closure of more than 100 injection wells in the casing damage area seriously affects the production of oil fields. The means of prevention and control are not informed, and the pertinence of the problem is poor, resulting in a lack of active monitoring of casing damage. Understanding the mechanism of casing damage is the key point to preventing, controlling, and managing casing damage on weak horizontal structure surfaces. Therefore, establishing a laboratory experimental device that simulates the sliding casing damage on a horizontal crack surface and reveals the mechanism of regional casing damage is critical.

It is important to verify the mechanism of standard layer shear-type casing damage through laboratory experiments $[15,16]$. However, owing to the limitations of experimental conditions and measurement methods, there are only direct dynamic shear-type casing damage experiments and underground mining ground deformation experiments. Sun [17] used a high-strength expansion agent to simulate formation stress; they inserted the simulation casing into the middle of the device, then inserted the expansion agent into one side of the experimental device, and, through the expansion agent, simulated the formation near the wellbore to shear the casing directly. Yin [18] conducted a direct shear test on a J55 casing with a TS-1 casing damage testing machine independently developed for in situ stress by the Laboratory of China Petroleum Exploration and Development Research Institute. The above two experiments simulated the formation of shear-type casing damage, but the actual casing damage process was greatly simplified in the experiments. In the experiments, the source of shear force was a direct thrust from two sides, but it could not explain the source of shear stress in the actual formation. In addition, there are no other reports on laboratory experimental devices for shear-type casing damage in the petroleum development field.

In an indoor physical simulation experiment of formation deformation in the mining field, Gong et al. [19] established a simulation experiment device for mining subsidence under complex geological conditions by using a similar material model with a scale of $1: 200$, model frame length of $2.1 \mathrm{~m}$, and height of $1 \mathrm{~m}$. The model was divided into 10 layers. It was laid in layers, and the layers were separated using an appropriate amount of mica powder. Zou and Chai [20] established a similar two-dimensional model test-bed using similar materials for simulated formation and measured the displacement state of the simulated formation after mining using laser reflection. However, the above experimental equipment was mainly aimed at underground air excavation to surface deformation and cannot determine the role of regional formation pore pressure difference [21]. The slip of the horizontal weak structural surface was caused by the relative slip between layers inside the formation, which was quite different from the measurement purpose of this experiment. In addition, there are no reports on laboratory test equipment and methods for shear-type casing damage caused by formation slip.

In this study, we propose a set of experimental devices that can simulate and measure formation slip. Based on the abnormal similarity theory with different horizontal and vertical scale similarity ratios, we carried out a formation slip simulation experiment under injection-production interregional pressure difference. The corresponding measurement method and experimental steps of formation slip were designed according to the slip characteristics of the mud-shale crack surface. Based on the abnormal similarity theory, the corresponding relationship between the experimental model and the prototype formation slip was established, and the formation slip at different positions under different conditions was measured and compared with the theoretical calculation results, and the factors influencing the formation slip were analyzed.

\section{Materials and Methods}

2.1. Experiment Method Based on the Similarity Model. The formation swelling and deformation caused by pore pressure changes are from the underground target layer to several hundred meters above the ground and several thousand meters in the horizontal direction, which reflects two prominent problems: a big volume is involved [22-25] and the great difference between horizontal and vertical proportions. The sliding layer is not a water flooding reservoir, but the nonproduction horizontal layer is approximately $70 \mathrm{~m}$ above it. The geological conditions are shown in Figure 1.

To solve the above problems, the simulated formation material was used instead of the actual formation, and a similar method was adopted to conduct the simulation experiment. Model experiments with different aspect ratios were designed according to the characteristics of the formation. The dimensional analysis method ( $\pi$ theorem) is applied to derive the similarity relationship between each physical quantity and determine the similarity constant of each physical quantity. In this experiment, the horizontal and vertical dimensions of the geometric parameters were analyzed with different scaling coefficients, and the length dimensions representing the horizontal and vertical directions were taken as different dimensions, $\left[L_{r}\right]$ and $\left[L_{z}\right]$, respectively. 


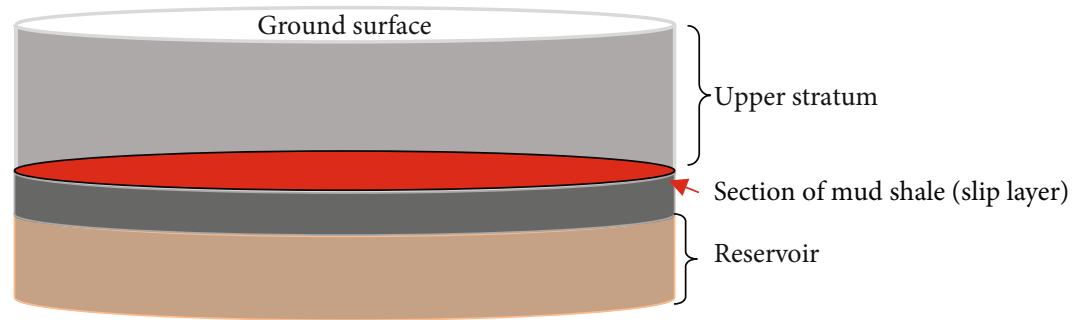

Figure 1: The geological conditions of slip layer.

According to the definition of each physical quantity, the dimensions of each physical quantity based on the above assumptions were obtained, as shown in Table 1 .

$D$ is the radial size (m) $H$ is the vertical dimension (m), $u$ is the radial displacement $(\mathrm{m}), w$ is the vertical displacement $(\mathrm{m}), \sigma_{r}$ is the radial stress $(\mathrm{MPa}), \sigma_{z}$ is the vertical stress $(\mathrm{MPa}), \varepsilon_{r}$ is the radial strain (nondimensional), $\varepsilon_{z}$ is the vertical strain (nondimensional), $E_{r}$ is the radial Young's modulus (MPa), $E_{z}$ is the vertical Young's modulus (MPa), $\mu_{z r}$ is the radial Poisson's ratio (nondimensional), and $\mu_{r z}$ is the nondimensional vertical Poisson's ratio.

In this physical simulation experiment, the dimensions $[T]$ and $[M]$ corresponding to the basic dimension are determined in proportion, so only the change in dimension $[M]$ needs to be considered. Therefore, $D, H$, and $E_{r}$ are taken as the basic dimensions to obtain the dimensionless $\pi$ terms of other physical quantities, as shown in Table 2.

The horizontal and vertical similarity ratios of the physical model and formation prototype were different. According to the distortion compensation model, the respective $\pi$ terms are assumed to form a product relation. Then, the relation between the independent $\pi$ terms is as follows:

$$
\pi=\left(A_{1} \pi_{a_{1}}^{e_{1}}\right) \cdots\left(A_{i} \pi_{a_{i}}^{e_{i}}\right) f\left(\pi_{u_{1}}, \pi_{u_{2}}, \cdots\right)
$$

where $\pi_{a i}$ is the $\pi$ term with dimensional parameters. When the parameters of some similar materials fail to meet the similarity ratio requirements in model design and material selection, they distort the model system. $\pi_{u 1}$ and $\pi_{u 2}$ are dimensionless parameter $\pi$ terms, $e_{i}$ is distorted idempotent, and $A_{i}$ is an infinite constant.

The prediction coefficient $\delta_{i}$ generated by model distortion is expressed as follows:

$$
\delta_{i}=\left(\beta_{1}^{-e_{1}}\right) \cdots\left(\beta_{i}^{-e_{i}}\right)\left[\frac{f\left(\pi_{u 1}, \pi_{u 2}, \cdots\right)_{p}}{f\left(\pi_{u 1}, \pi_{u 2}, \cdots\right)_{m}}\right],
$$

where $\delta_{i}$ is the coefficient of prediction, $\beta_{i}$ is the distortion coefficient of each parameter $\pi$ term, $\beta_{i}=\pi_{i m} / \pi_{i p}$, and $\pi_{i m}$ and $\pi_{i p}$ are dimensionless $\pi$ terms for each parameter. The subscript " $p$ " represents the parameters of the formation prototype, and the subscript " $m$ " represents the parameters of the experimental model.

Thus, the similarity ratio relation can be obtained as follows:

$$
\left\{\begin{array}{l}
C_{u}=\delta_{1} C_{D}, \\
C_{w}=\delta_{2} C_{H}, \\
C_{\sigma_{r}}=\delta_{3} C_{E_{r}}, \\
C_{\sigma_{z}}=\delta_{4} C_{D}{ }^{-2} C_{H}^{2} C_{E_{r}}, \\
C_{E_{z}}=\delta_{5} C_{D}{ }^{-2} C_{H}^{2} C_{E_{r}}, \\
C_{\mu_{z r}}=\delta_{6} C_{D}{ }^{-2} C_{H}^{2}, \\
C_{\mu_{r z}}=\delta_{7} C_{D}{ }^{2} C_{H}{ }^{-2},
\end{array}\right.
$$

where $C_{f}$ is the similarity ratio of the parameter $f=(D$ $\left., H, u, \cdots, \mu_{r z}\right)$ and $\delta_{i}$ is the prediction coefficient generated by the model distortion.

Both experimental models and stratigraphic prototypes, simulated stratigraphic materials, and stratigraphic rocks can be considered as isotropic materials. Therefore, the following relations are obtained:

$$
\delta_{3}=\frac{C_{D}^{2}}{C_{H}^{2}}, \quad \delta_{4}=\delta_{5} \frac{C_{D}^{2}}{C_{H}^{2}}, \quad \delta_{6}=\delta_{7} \frac{C_{D}^{4}}{C_{H}^{4}}
$$

Then, the similarity ratio of the dimensionless parameters is obtained as follows:

$$
C_{\varepsilon_{r}}=\frac{\varepsilon_{r p}}{\varepsilon_{r m}}=\frac{C_{E_{r}}}{C_{\sigma_{r}}} \frac{1+2 \mu_{r z p}}{1+2 \mu_{r z m}}=\frac{C_{H}^{2}}{C_{D}^{2}} \frac{1+2 \mu_{r z p}}{1+2 \mu_{r z m}}, \quad C_{\varepsilon_{z}}=\frac{\varepsilon_{z p}}{\varepsilon_{z m}} \frac{C_{E_{z}}}{C_{\sigma_{z}}} \frac{1+2 \mu_{r z p}}{1+2 \mu_{r z m}}=\frac{C_{H}^{2}}{C_{D}^{2}} \frac{1+2 \mu_{r z p}}{1+2 \mu_{r z m}} .
$$


TABLE 1: Dimensions of physical quantities based on different horizontal and vertical length ratios.

\begin{tabular}{|c|c|c|c|c|c|c|c|c|c|c|c|c|}
\hline Basic dimensions & $D$ & $H$ & $u$ & $w$ & $\sigma_{r}$ & $\sigma_{z}$ & $\varepsilon_{r}$ & $\varepsilon_{z}$ & $E_{r}$ & $E_{z}$ & $\mu_{z r}$ & $\mu_{r z}$ \\
\hline$[M]$ & 0 & 0 & 0 & 0 & 1 & 1 & 0 & 0 & 1 & 1 & 0 & 0 \\
\hline$\left[L_{\mathrm{r}}\right]$ & 1 & 0 & 1 & 0 & 0 & -2 & 0 & 0 & 0 & -2 & 2 & -2 \\
\hline$\left[L_{z}\right]$ & 0 & 1 & 0 & 1 & -1 & 1 & 0 & 0 & -1 & 1 & -2 & 2 \\
\hline$[T]$ & 0 & 0 & 0 & 0 & -2 & -2 & 0 & 0 & -2 & -2 & 0 & 0 \\
\hline
\end{tabular}

In the design of a structure dissimilar model, factors such as type, material, manufacturing conditions, loading capacity, arrangement of measuring points, and equipment conditions should be considered comprehensively in the geometric size of the model. An experimental model that is too small will lead to high requirements for experimental processing and instrument measurement accuracy, and an excessively large experimental model will inconvenience the experiment. Therefore, it is necessary to consider these factors in selecting the experimental size and materials. For this experiment, given the lateral and vertical dimensional similarity ratio and mechanical parameters of the simulated stratum, the similarity ratio of the other parameters and the corresponding prediction coefficients can be obtained.

Considering the elastic modulus, strength, and actual processing capacity of each material comprehensively, soft polyvinyl chloride was selected as the simulated formation material of the similar model. Considering that the actual water injection pressure of the experimental model was generally less than $1.5 \mathrm{MPa}$, the simulated stress of the formation material is in the linear elastic deformation range. At the same time, under the action of interregional pore pressure, the formation prototype was in the linear elastic deformation range regardless of the oil layer, overburden, or even the surface position and did not involve nonlinear yield deformation and failure. Therefore, for the experiments, this polymer material could be used as a simulated stratum instead of rocks.

Thus, the experimental model and formation prototype parameters were obtained, as shown in Table 3.

According to the similarity theory, the similarity ratio and prediction coefficient of each parameter between the actual stratigraphic prototype and the experimental model of the upper and lower layers are shown in Tables 4 and 5, respectively.

The values of the corresponding parameters of the actual formation can be obtained by multiplying the parameters of the simulated formation in the experimental model with the corresponding parameter similarity ratio.

2.2. Equipment. The crack and slip of the horizontal weak structural surface at the bottom of the Nen'er member is caused by the vertical deformation of the bottom oil layer, which is characterized by no stress at the top and deformation at the bottom under the action of formation pressure. However, deformation through the formation pore pressure requires the accumulation of a large thickness, which cannot be achieved by laboratory experiments to produce the bottom deformation of the formation slip. In a previous finite element study, bottom water injection pressurization pressure was similar to that of interregional formation pore pressure. For this reason, we used bottom water injection pressurization to simulate the interregional formation pressure difference. However, this type of experimental equipment is unprecedented and requires additional design and manufacturing. To experimentally achieve formation slip deformation with different radial sizes, a flange adapter was used, which could correspond to the experimental materials with diameters of $250 \mathrm{~mm}, 300 \mathrm{~mm}$, and $400 \mathrm{~mm}$. In this experiment, a two-dimensional axisymmetric model was used. To ensure that the deformation of the equipment is very small when simulating formation deformation, steel equipment with a height of $1000 \mathrm{~mm}$ and a wall thickness of $40 \mathrm{~mm}$ that can withstand a pressure of $5 \mathrm{MPa}$ without leakage was used. The maximum bearing capacity of the designed physical simulation device of a weak structure surface slip under the action of the interlayer pressure difference was $5 \mathrm{MPa}$, and the diagram of its structure is shown in Figure 2.

In the experiment, a combination of a manual pump and a constant-flux pump was used to inject liquid into the device to achieve pressurization. The maximum allowable pressure of the constant-flux pump was $42 \mathrm{MPa}$, the minimum flow rate was $0.001 \mathrm{~mL} / \mathrm{s}$, and the maximum flow rate was $1.000 \mathrm{~mL} / \mathrm{s}$. First, the manual pump was used for rapid pressurization. Then, when all the liquid in the pump was pumped into the equipment to reach the experimental pressure, the constant-flux pump was used for slow and accurate pressurization until the pressure required by the experiment was reached. The manual liquid booster pump, advection pump, and formation deformation test device were connected through six channels, and a pressure gauge was installed on the six channels to measure the internal liquid pressure (Figure 2).

2.3. Method for Measuring Formation Slip. By connecting the water injection pressurization system with the main experimental equipment, simulated formation expansion can be achieved. The vertical displacement of the formation was accurately measured with a displacement measurement device with an accuracy of $0.001 \mathrm{~mm}$ and a range of $15.000 \mathrm{~mm}$. For continuous and stable measurements of the formation with the displacement measurement device, a custom steel plate was made to fix it. The middle and both ends of the customized steel plate were equipped with a drill hole. The drill hole in the middle was used to install the 
TABLE 2: The dimensionless $\pi$ term of each physical parameter.

\begin{tabular}{lccccc}
\hline Number & Parameter & Dimensionless $\pi$ term & Number & Parameter & Dimensionless $\pi$ term \\
\hline 1 & Radial displacement & $\pi_{1}=u / D$ & 2 & Vertical displacement & $\pi_{2}=w / H$ \\
3 & Radial Young's modulus & $\pi_{3}=\sigma_{r} / E_{r}$ & 4 & Vertical stress & $\pi_{4}=\sigma_{z} / u^{-2} w^{2} E_{r}$ \\
5 & Vertical Young's modulus & $\pi_{5}=E_{z} / u^{-2} w^{2} E_{r}$ & 6 & Vertical Poisson's ratio & $\pi_{6}=\mu_{z r} / u^{-2} w^{2}$ \\
7 & Vertical Poisson's ratio & $\pi_{7}=\mu_{r z} / u^{2} w^{-2}$ & & & \\
\hline
\end{tabular}

TABle 3: Parameter comparison between the similar model and formation prototype.

\begin{tabular}{lcc}
\hline Formation parameters & Similar model & Actual formation model \\
\hline Elastic modulus & $2.04 \mathrm{GPa}$ & $25 \mathrm{GPa}$ \\
Poisson's ratio & 0.31 & 0.25 \\
Formation diameter & $250 \mathrm{~mm}, 300 \mathrm{~mm}, 400 \mathrm{~mm}$ & $1500 \mathrm{~m}, 1800 \mathrm{~m}, 2400 \mathrm{~m}$ \\
The total thickness of the formation & The upper formation $15.0 \mathrm{~mm}$ & The upper formation $600 \mathrm{~m}$ \\
& The lower formation $5.0 \mathrm{~mm}$ & The lower formation $200 \mathrm{~m}$ \\
\hline
\end{tabular}

TABLE 4: Each prediction coefficient of the similar model.

\begin{tabular}{|c|c|c|c|}
\hline \multicolumn{2}{|c|}{ Prediction coefficient generated by model distortion } & \multicolumn{2}{|c|}{ Prediction coefficient generated by model distortion } \\
\hline Transverse modulus of elasticity & $\delta_{3}=0.0900$ & Longitudinal stress & $\delta_{4}=0.0081$ \\
\hline Longitudinal modulus of elasticity & $\delta_{5}=0.0900$ & Transverse Poisson's ratio & $\delta_{6}=0.0726$ \\
\hline Longitudinal Poisson's ratio & $\delta_{7}=8.9606$ & & \\
\hline
\end{tabular}

TABLE 5: Similarity ratio of parameters between the actual formation prototype and similar model.

\begin{tabular}{|c|c|c|c|c|c|c|c|c|c|c|}
\hline & $D$ & $H$ & $\sigma_{r}$ & $\sigma_{z}$ & $\varepsilon_{r}$ & $\varepsilon_{z}$ & $E_{r}$ & $E_{z}$ & $\mu_{z r}$ & $\mu_{r z}$ \\
\hline Similarity ratio & 12000 & 40000 & 62.12 & 62.12 & 0.662 & 0.662 & 10.288 & 10.288 & 7.353 & 7.353 \\
\hline
\end{tabular}

displacement measurement device. The two ends could be fitted to the flange of the formation-deformation measuring device.

The soft adhesive of epoxy resin selected in the formation slip experiment, with an operation time of $4 \mathrm{~h}$ and solidification time of $12 \mathrm{~h}$, was used to simulate the casing deformation and slip under the formation-deformation condition. The epoxy resin adhesive was formed by gradual thickening and condensation after mixing liquids $\mathrm{A}$ and $\mathrm{B}$. The hardness and softness of the epoxy resin could also be adjusted according to the different formulations and solidification times. In this experiment, a soft adhesive with a solidification time of $12 \mathrm{~h}$ was selected. Both liquids $A$ and $B$ were of this type of epoxy resin adhesive and were low-viscosity solutions. After mixing, the viscosity gradually increases; good fluidity was maintained in the first $30 \mathrm{~min}$, and the initial setting time was $4 \mathrm{~h}$. From $4 \mathrm{~h}$ to $10 \mathrm{~h}$, it became a solid, and the mobility almost disappeared, but the plasticity was strong; that is, after the deformation under the action of an external force, the shape could not be recovered. After $10 \mathrm{~h}$, the plastic characteristics gradually trans- formed into elastic characteristics. After $12 \mathrm{~h}$, the epoxy resin adhesive was set with strong elasticity and a certain memory effect; that is, after the external force was applied to deform it, the deformation could be recovered by removing the external force. The $\mathrm{AB}$ epoxy resin adhesive maintained a long fluidity time. In the slip experiment of a weak horizontal structural surface, the amount of expansion of the simulated material should be kept constant; thus, a material with moderate solidification time was needed to simulate the deformation condition of the casing in maintaining formation uplift. However, the preparation process took a long time, so the epoxy resin needed to maintain a certain period of fluidity before solidification. The solidified epoxy resin adhesive maintained its deformed state during solidification and returned to its original state when the force was removed. The epoxy resin adhesive is a fluid before curing and can deform with the internal deformation of the casing. Soft epoxy adhesives have good scalability after curing and are not easily damaged by large deformations. This type of epoxy resin deforms during disassembly, but the deformation is within the elastic range. After the epoxy resin adhesive was 

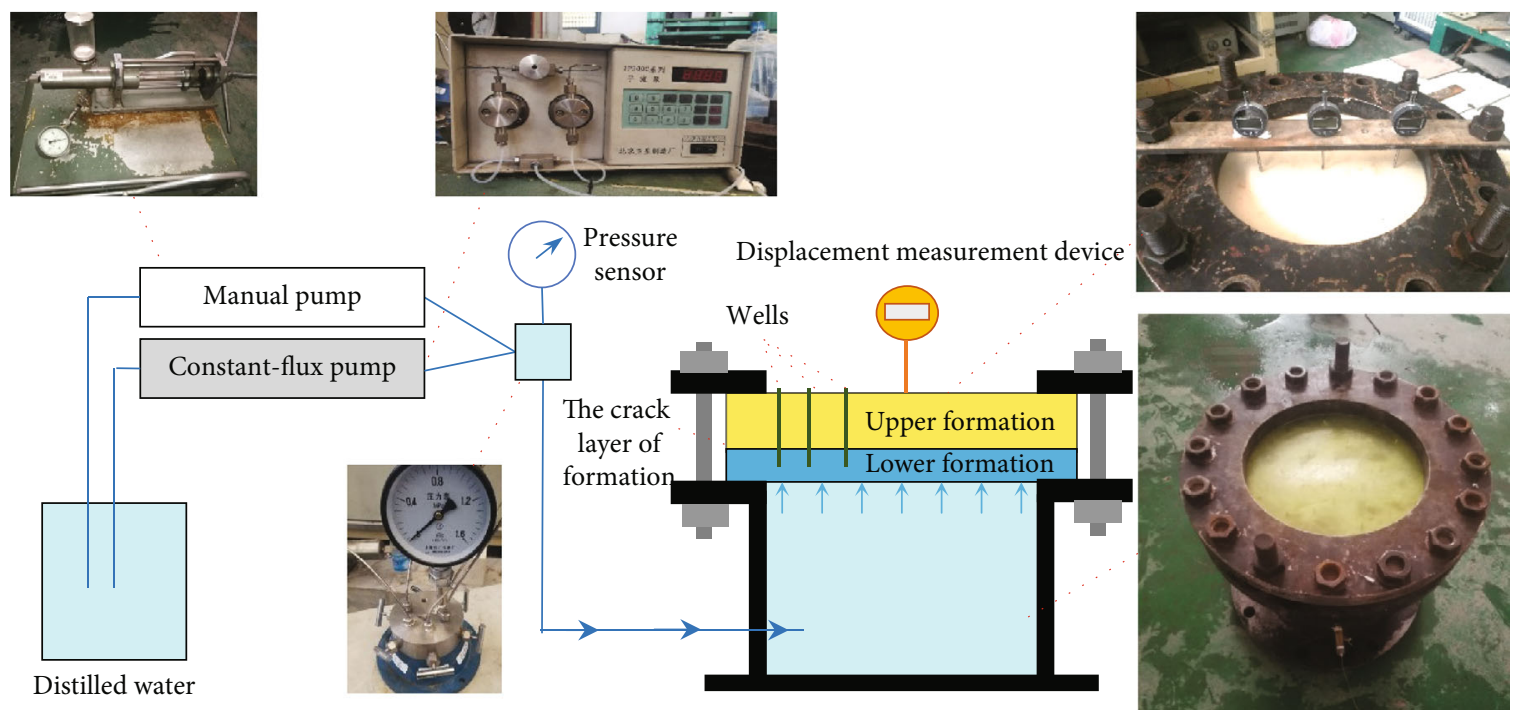

FIGURE 2: The connection diagram of the formation deformation experiment and stress measuring devices.

removed, it returned to the shape of the formation slip and did not affect the slip measurement results.

The epoxy resin was solidified in the hole, and after removing all external forces, the epoxy resin deformed to the solidified shape, that is, the hole position slippage state due to the formation expansion. This method can be used to easily observe the variation characteristics of slip at different planes for formation expansion induced by hydraulic fracturing. To avoid the mutual interference of the stress concentration near the hole, the spiral layout mode was selected after observing the hole layout. The holes of the simulated material were all distributed on the helix. This ensured that the spacing between the holes was the same and the straight distance between the holes was not too short. In the experiment, the distance between the actual holes was extended to an average of $34.6 \mathrm{~mm}$ by spiral distribution drilling. The shortest distance between two holes was $25.4 \mathrm{~mm}$. The stress between holes with a diameter of $2 \mathrm{~mm}$ was very small.

If the method of injecting epoxy resin directly into the simulated formation was adopted, the epoxy resin glue would be completely cemented in the inner wall of the observed hole, and the epoxy resin glue would not be removable or would be seriously damaged after removal. Therefore, a method of inserting a polytetrafluoroethylene (PTFE) pipe into the hole to simulate the casing was designed. PTFE has a strong resistance to organic solvents and is not easy to glue. The epoxy resin adhesive did not stick to the PTFE after solidification and could be easily removed. In addition, in order to prevent the leakage of epoxy resin glue during injection and the experiment, a length of $1-2 \mathrm{~mm}$ at the bottom of the simulated casing of the PTFE pipe was sealed in advance. Because the epoxy resin adhesive was transparent, dye was added to the epoxy resin adhesive to change its color in order to facilitate observation in the experiment; the dye was very low in content, with only $0.1 \%$ concentration dying the epoxy resin. After the formation slip experiment was completed, the

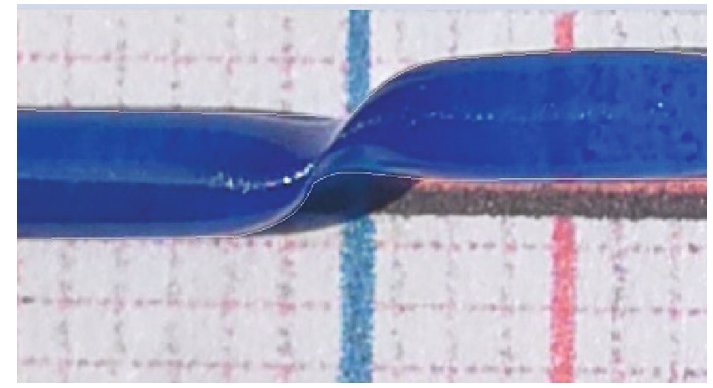

Figure 3: Enlarged image of simulated wellbore deformation.

morphology of the epoxy resin glue was the internal morphology of the observation hole. Owing to the small amount of deformation in the observation of the inner shape of the hole, there would be a large error in the direct measurement using the measuring tool; thus, the deformation could not be measured directly. In the actual measurement process, the deformation was obtained by enlarging a picture of the epoxy resin for accurate measurement and then reducing the corresponding multiple, as shown in Figure 3.

Through the magnification measurement method, the transverse shear deformation at the position of the crackslip surface in the observation hole was obtained. Combined with the relationship between the formation slip and transverse shear deformation of the observation hole, the interlayer slip at the observation hole position was calculated, as shown in the following equation:

$$
s_{i}=s_{i(w)}+d_{w} \alpha_{w}-D_{c}
$$

where $s_{i}$ is the slip amount of the hole at the position numbered point $i(\mathrm{~mm}), s_{i(w)}$ is the transverse shear deformation of the bedding crack surface inside the hole at the point numbered point $i(\mathrm{~mm}), d_{w}$ is the bit diameter $(\mathrm{mm}), \alpha_{w}$ 


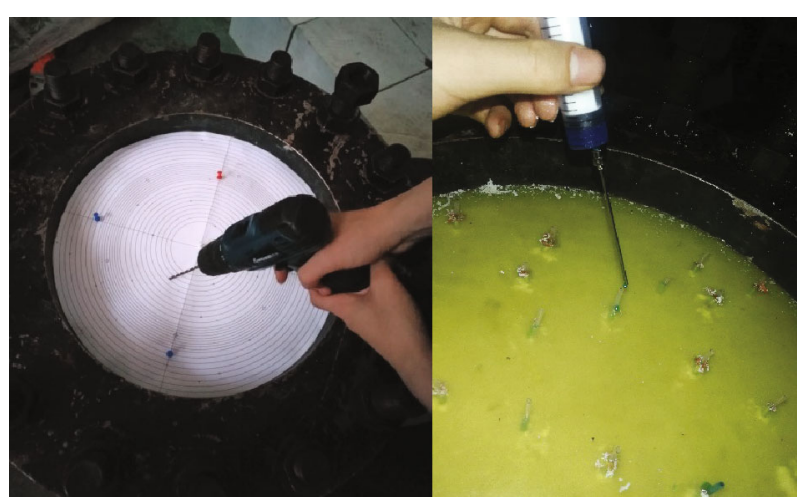

FIGURE 4: Drilling and gluing.

is the reaming rate of the bit (for PVC, an easy-to-drill material, the reaming rate is generally $5 \%$ ), and $D_{c}$ is the simulated casing outer diameter $(\mathrm{mm})$.

\subsection{Experimental Procedure}

(1) The flange conversion joint corresponding to the experimental size of the experimental material was installed on the experimental equipment, and the water tank was filled with water in advance

(2) The simulated material was fixed to an experimental device. The simulated stratum was placed in the experimental device according to the designed sequence, and the bottom of the simulated stratum was sealed to prevent liquid leakage. The top bolt was tightened to fix the simulated formation boundary. Subsequently, the sealing and connectivity of the experimental device were examined

(3) The boreholes were marked on the simulated formation device according to the designed position, and the simulated boreholes were drilled with an electric drill, with the drilling depth guaranteed to meet the experimental requirements. This is shown in Figure 4

(4) Timing immediately started at the configuration of the epoxy resin adhesive. The prepared simulated casing was inserted into the simulated well, and the configured epoxy resin adhesive was injected into the simulated casing with a syringe installed with a long glue injection needle. The casing ensures that the epoxy resin adhesive will not flow into the microtensioned layer when the formation slips. The thickness of the casing was $0.1 \mathrm{~mm}$, which hardly changed when the formation was deformed, and it did not affect the experimental results. The viscosity of the epoxy resin adhesive increased sharply. After $15 \mathrm{~min}$, although the epoxy resin adhesive is still a fluid, it cannot be injected into the casing through a syringe, resulting in the failure of the experiment. Therefore, all epoxy resins should be injected into the simulated casing within $15 \mathrm{~min}$

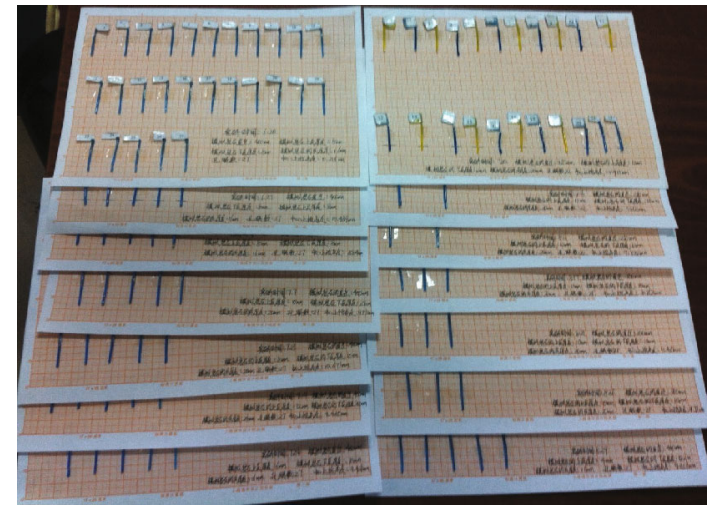

FIgURE 5: The borehole interior morphology after the formation slip experiment.

(5) The displacement measuring device was installed on the formation simulation device to detect the swelling displacement of the simulated material

(6) A manual pump was used to inject water into the pressurizing device and to apply pressure to the simulated material for recording the longitudinal deformation and water injection pressure data of the formation. The changes in value of the pressure gauge and displacement measuring device were observed. The water injection pressure in the experiment is different from the pore pressure in the actual formation; therefore, it cannot be directly used as the pore pressure of the formation. It must be equivalent to the pore pressure of the reservoir required by the simulation of the uplift of the formation center in the experiment and the corresponding uplift of the actual formation. During this period, it is necessary to find the corresponding relationship between the pore pressure variation and the experimental water injection pressure by numerical simulation. When the displacement measurement device reached the experimental design of longitudinal deformation, the pressure was stopped to keep the pressure unchanged. The above steps were carried out within $1 \mathrm{~h}$ after the epoxy resin adhesive was mixed, that is, before the initial setting of the epoxy resin adhesive

(7) A constant-flux pump was used to keep the pressure value of the bottom booster unchanged. Then, the epoxy resin adhesive took $12 \mathrm{~h}$ to set

(8) After $12 \mathrm{~h}$, the drainage valve was opened to relieve pressure. Then, the pressure of the experimental equipment was removed, and the simulated casing in the simulated formation was removed. After the simulated casing was cut open, the epoxy resin adhesive reflecting the formation slip shape of each simulated well was removed and pasted on the coordinate paper with formation information to complete the slip measurement 
TABLE 6: Experimental parameters of each group.

\begin{tabular}{lcccc}
\hline $\begin{array}{l}\text { Serial } \\
\text { number }\end{array}$ & $\begin{array}{c}\text { The interregion formation pressure } \\
\text { difference }(\mathrm{MPa})\end{array}$ & $\begin{array}{c}\text { Abnormal formation } \\
\text { pressure area }(\mathrm{m})\end{array}$ & $\begin{array}{c}\text { The depth of } \\
\text { formation }(\mathrm{m})\end{array}$ & $\begin{array}{c}\text { The depth of horizontal weak } \\
\text { structure surface }(\mathrm{m})\end{array}$ \\
\hline 1 & 1.59 & 1500 & 800 & 600 \\
2 & 1.98 & 1500 & 800 & 600 \\
3 & 2.38 & 1500 & 800 & 600 \\
4 & 1.59 & 1800 & 800 & 600 \\
5 & 1.59 & 2400 & 800 & 600 \\
6 & 1.59 & 2400 & 640 & 600 \\
7 & 1.59 & 2400 & 960 & 600 \\
8 & 1.59 & 2400 & 800 & 560 \\
9 & 1.59 & 2400 & 800 & 680 \\
\hline
\end{tabular}

\section{Experimental Result}

The experimental device we developed was used to carry out several groups of formation slip experiments, and the formation slip distribution was measured under different pressures, simulated formation diameters, reservoir-buried thicknesses, and crack surface depths, and the internal morphology of the simulated well after deformation was obtained, as shown in Figure 5.

The mechanical parameters of the experimental model and the formation prototype were based on the data in Table 3. We conducted a total of 14 groups of experiments, nine of which were effective. Nine valid sets of experimental data are listed in Table 6.

The slip distributions on the crack surface between the top and bottom formations under different water injection pressures (serial numbers 1, 2, and 3) were compared for a simulated formation diameter of $250 \mathrm{~mm}$, as shown in Figure 6.

The slip of the crack surface is a relative displacement, that is, the difference between the radial displacements of the upper and lower layers of the horizontal crack surface. In the simulation experiment, the displacement of the upper and lower parts of the crack surface could not be measured, and the slip could only be determined by observing the solidification shape of the epoxy resin adhesive in the borehole. The experimental results showed that after the deformation of the simulated formation bottom, the simulated formation above was deformed by pressure from the bottom. Although the layer in the middle of the simulated formation could maintain the longitudinal continuity of the stratum, it had a relative displacement in the horizontal direction. Although the surrounding area of the simulated formation was completely fixed and the center of the formation did not slip under symmetric action, there was also a slip in the middle. It can be seen from Figure 6 that under different vertical displacements of the formation center, the variation trend of the interlayer slip was the same, which first increased and then decreased with an increase in distance from the center. By comparing the slippage of different vertical displacements at the center of the formation, it was found that the slippage on the horizontal crack surface of the formation had a linear relationship with the longitudinal displacements at the center.

The actual slip of the formation can be obtained by multiplying the slip value by the transverse proportionality coefficient. The interregional formation pressure difference did not correspond to the water injection pressure at the bottom of the test equipment. The pressure difference between the adjacent regions of the actual formation can be calculated according to its effect on the formation. First, the corresponding relationship between the formation pressure difference and the vertical deformation of the surface center was calculated based on the finite element simulation. Then, according to the simulated uplift height multiplied by the longitudinal length ratio, the actual maximum vertical deformation height of the formation can be obtained to determine the regional formation pressure difference of the actual formation. Through calculations, it was determined that in the actual formation corresponding to the experimental conditions, the slip amounts at different positions corresponding to the interregional pressure difference (serial numbers 1, 2, and 3) were as in Figure 7.

Through scale conversion, the size of the experimental model was converted to the actual size of the formation, as shown in Figure 7 . The origin of the $r$ coordinate was the center of the abnormally high-pressure area, and the position $r=1500 \mathrm{~m}$ was the center of the low-pressure area. The slip of the crack surface occurred between the highpressure and low-pressure zones, and the slip first increased and then decreased. In actual oil field production, formation slip will shear the wellbore on the slip surface, resulting in shear-casing damage. In the Daqing Oilfield, the crack surface was uncemented to prevent shear-casing damage, leaving room for formation slip. When the formation slip exceeded $60 \mathrm{~mm}$, the formation would cause the shear deformation of the casing and affect the production of the oil and water wells. Based on this amount of slip, the maximum interregional formation pressure difference was $0.69 \mathrm{MPa}$ for no casing damage occurred on this field.

The range of the interregional formation pressure difference also affects the slip on the horizontal crack surface of the horizontal weak structure layer. Therefore, experiments with different diameters were performed to simulate 


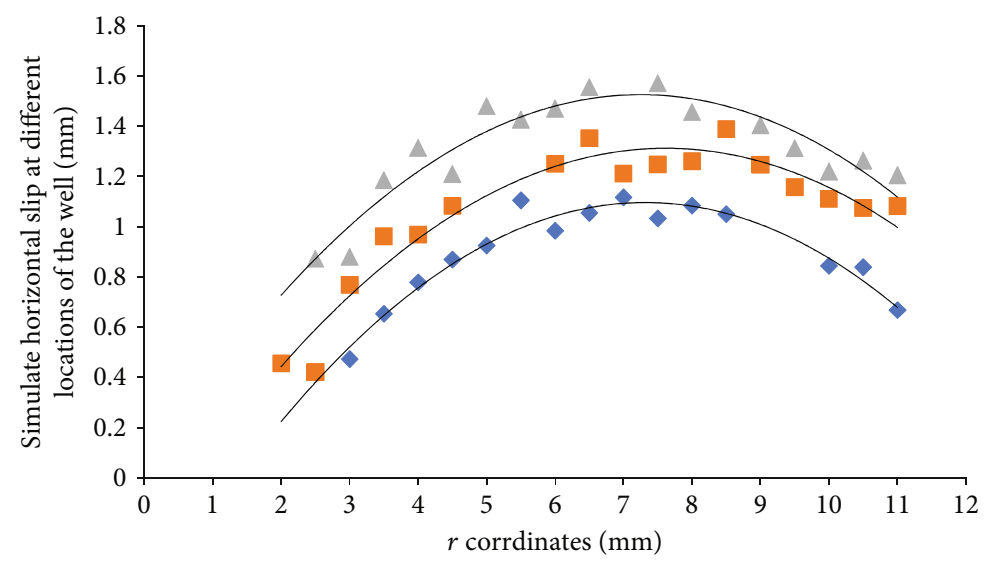

- Longitudinal displacement in the middle position $4.200 \mathrm{~mm}$

- Longitudinal displacement in the middle position $5.250 \mathrm{~mm}$

$\triangle$ Longitudinal displacement in the middle position $6.300 \mathrm{~mm}$

FiguRE 6: Trend diagram of the slippage experimental results in the mud-shale section under different pressures.

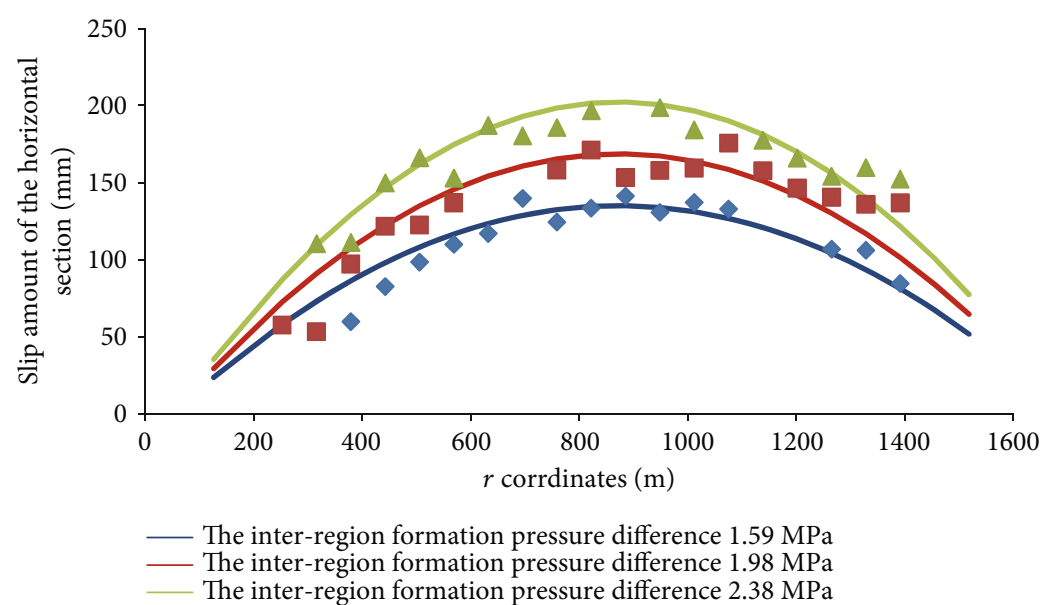

FiguRE 7: The section slippage in the actual formation of mud shale under different formation pore pressure difference between regions.

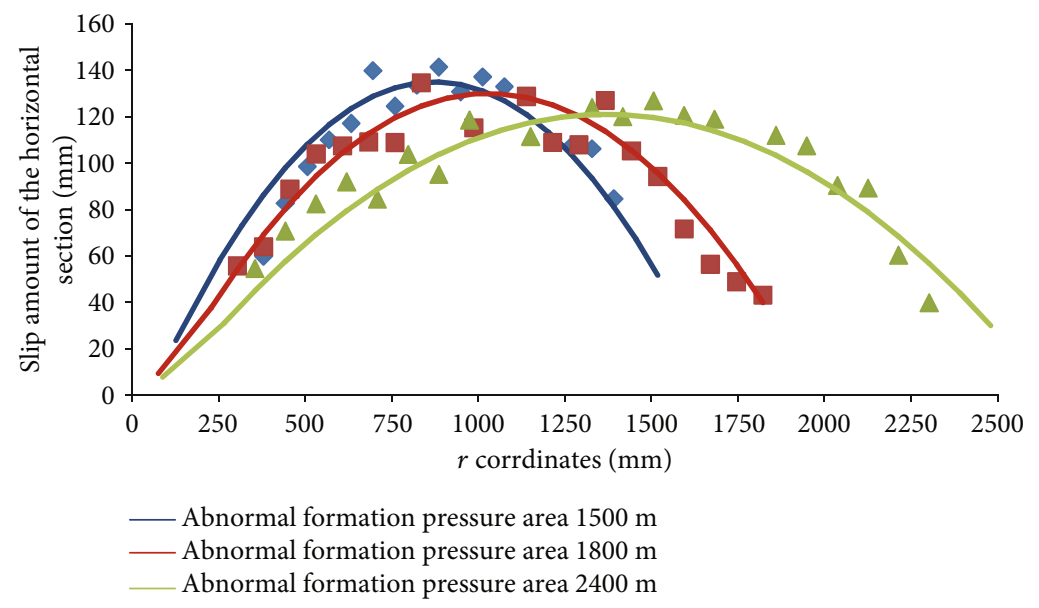

FIGURE 8: The section slippage in the actual formation of mud shale for a range of different formation pore pressure differences. 


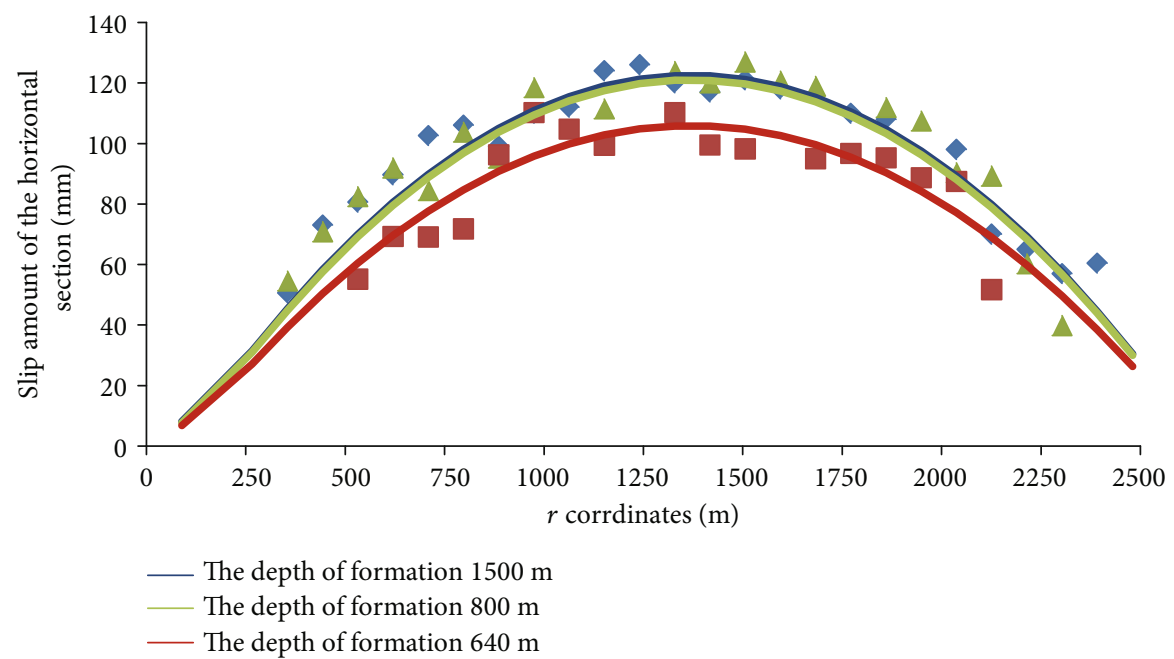

FIgURE 9: The section slippage in the actual formation of the mud-shale standard layer at different depths.

formation slip. The diameters of the experiment were $250 \mathrm{~mm}, 300 \mathrm{~mm}$, and $400 \mathrm{~mm}$ (serial numbers 1, 4, and 5). The interlayer slip was measured and analyzed where all the longitudinal displacements of the formation center were $4.20 \mathrm{~mm}$, and it was converted into the actual formation conditions under the formation pressure difference in the same area. The results are presented in Figure 8.

After transformation, the formation pressure difference between regions was $1.59 \mathrm{MPa}$. With an increase in the range of interregional formation pressure, the maximum value of slippage on the mud-shale crack surface decreased slightly and was extrapolated, and the influence range of the interzonal slippage increased. The top depth of the oil layer was different in different blocks, so the variation degree of slippage on the mud-shale crack surface would also change accordingly.

To study the effect of the reservoir depth on the interlayer slip, different simulated formation thickness experiments were carried out to analyze the formation slip under different standard depth conditions. The simulated material in this group was $400 \mathrm{~mm}$ in diameter, and the total thicknesses of the simulated formations were 24, 20, and $16 \mathrm{~mm}$. The corresponding total thicknesses of the actual formations were $960 \mathrm{~m}, 800 \mathrm{~m}$, and $640 \mathrm{~m}$ (serial numbers 7,5 , and 6). The relative position of the mud-shale standard layer remained unchanged, and the thickness ratio of the top and bottom layers was $3: 1$. Through the transformation of the measurement results to the actual formation, the slip distribution on the horizontal crack surface of the standard layer was calculated and obtained for an interregional formation pressure difference of $1.59 \mathrm{MPa}$ and different top depths of the oil layers, as shown in Figure 9.

In terms of numerical value and trend, with the increase in reservoir depth, the maximum slip on the mud-shale crack surface increased; however, the increase was small. Within the range of the reservoir top depth in the Daqing Oilfield, the slip varied by $25 \%$ at most. The maximum value of slip and the distribution law of slip showed no obvious changes in the three groups of experiments.
To determine the influence of depth on the slippage of the mud-shale crack surface, $400 \mathrm{~mm}$ was selected to simulate the formation and ensure that the total thickness of the simulated formation was uniformly $20 \mathrm{~mm}$. Three combined conditions of $13 \mathrm{~mm}: 7 \mathrm{~mm}, 15 \mathrm{~mm}: 5 \mathrm{~mm}$, and $17 \mathrm{~mm}: 3 \mathrm{~mm}$ thickness of the upper and lower layers were studied, and the corresponding horizontal crack surface depths were $520 \mathrm{~m}, 600 \mathrm{~m}$, and $680 \mathrm{~m}$, respectively (serial numbers 8,5 , and 9). Through the transformation of the measured results to the actual formation, the slip distribution on the horizontal crack surface of the standard layer with different top depths of oil layers was calculated and obtained when the interregional formation pressure difference was 1.59 $\mathrm{MPa}$, as shown in Figure 10.

The calculation results showed that the interlayer slip increased with the upward movement of the relative position of the standard layer. When the mud-shale standard layer was located in the middle of the oil layer and the surface, the maximum slip was caused by the interregional formation pressure difference. This law was very similar to the distribution law of shear stress; that is, under the action of interregional pressure difference, the formation shear stress accumulated from the bottom, reached a maximum in the middle of the formation, and became zero on the surface. In addition, from the calculation results, for different interregional formation pressure differences, action ranges, formation thicknesses, and crack surface depths, the comparison between the experimentally measured data and the theoretically calculated results was in good agreement. In the simulation experiment, a mud-shale standard interlayer slip was observed, the amount of interlayer slip under different conditions was measured, and the accuracy of the theoretical model of formation slip under the effect of interregional formation pressure difference was verified.

The experimental analysis showed that the interregional formation pressure difference between the bottom oil layers was the driving force for the slip of the mudshale standard layer in the formation, and the formation pore pressure did not need to act directly on the 


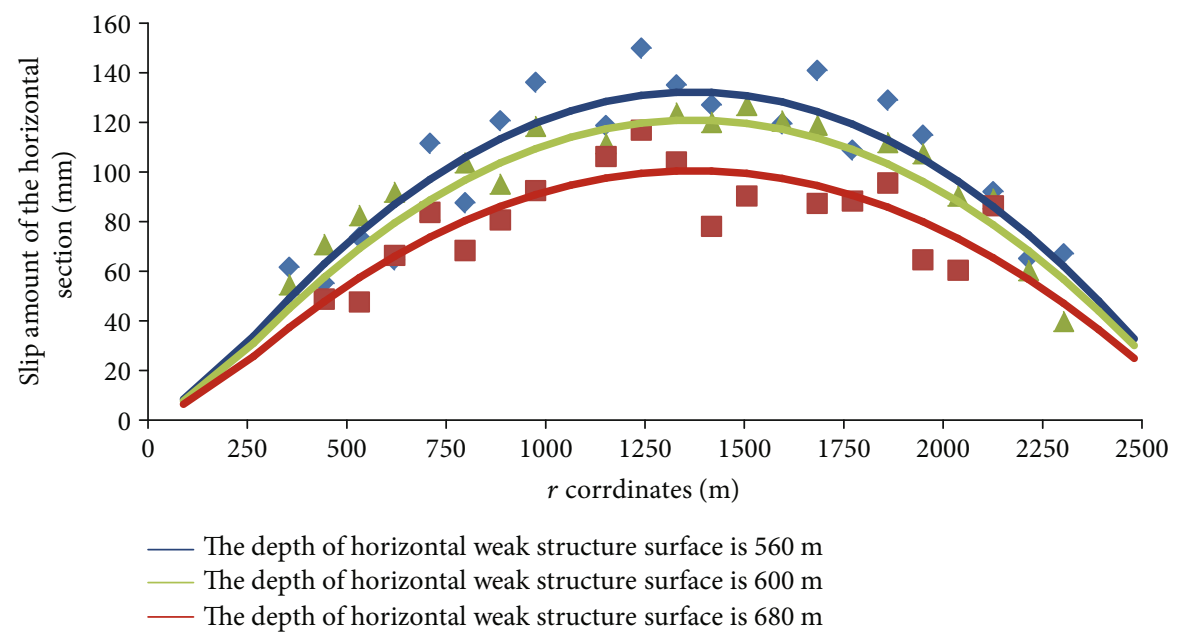

FIgURE 10: The section slippage of the actual formation of mud shale for different section depths.

formation where the crack surface was located. The interregional formation pressure difference acted on the formation below the crack surface at a certain distance; it could transfer the formation deformation to the crack surface and form the horizontal relative displacement through the uneven longitudinal deformation through the formation rock. When the distance of the interregion was greater than $1500 \mathrm{~m}$, with an increase in the distance between regions, the maximum slip amount generated by the pressure difference between regions on the crack surface decreased slightly. However, the influence range of the slip amount increased. Under the actual stratigraphic conditions, the formation with a deep oil layer but relatively shallow horizontal weak structure surface had a relatively large slip amount caused by cracks. In oilfield development, in order to prevent casing damage caused by formation slip, the interregional formation pressure difference should be reduced to less than $0.69 \mathrm{MPa}$ (taking Daqing Oilfield as an example). However, for formations with deep burial locations and relatively shallow horizontal weak structural surfaces, it should be emphasized to prevent and control the change in interregional formation pressure difference.

\section{Conclusions}

(i) In this study, the influence of formation slip due to interregional formation pressure difference was studied using the similarity model. This study solves the problem that indoor simulation experiments cannot be carried out because of the large gap between the horizontal and vertical ratios between the formation prototype and the experimental model. By reserving observation holes and placing soft epoxy resin in the holes and gradually solidifying it under loading conditions, the slip amount of the formation can be measured

(ii) The interregional formation pressure difference can cause relative slip at the weak horizontal structural surface. Shear-casing damage occurs when the local slip exceeds the limit that the wellbore can bear. The pressure difference between the safe zones to prevent casing damage can be obtained from the limit values of the maximum formation slip and shearcasing slip. Through this method, the safe interregion formation pressure difference in the Daqing Oilfield is $0.69 \mathrm{MPa}$

(iii) The maximum slip amount is located on the weak structural surface between the high- and lowpressure zones. An increase in the interregion spacing can affect the slip range. The formation with a deep burial location and a relatively shallow crack surface will result in a more serious formation slip

\section{Data Availability}

The data used to support the findings of this study are included within the article.

\section{Conflicts of Interest}

The authors declare that they have no conflicts of interest regarding the publication of this paper.

\section{Acknowledgments}

This research was supported by the National Natural Science Foundation of China (Youth Project) (Grant No. 51804076), Joint Guidance Project of Natural Science Foundation of Heilongjiang (Grant No. LH2021E016), China Postdoctoral Science Foundation (Grant No.2021M690528), Postdoctoral Projects in Heilongjiang Province (Grant No. LBH-Z20035), Youth Science Foundation of Northeast Petroleum University (Grant no. 2018QNL-19), and Research Initiation Foundation of Northeast Petroleum University (Grant No. 2019KQ14). 


\section{References}

[1] L. He, Y. Ye, W. Qunyi, Y. Jianwen, and D. Huilan, "Challenges and countermeasures facing casing damage in Daqing oilfield," in European Association of Geoscientists \& Engineers, 67th EAGE Conference \& Exhibition, pp. 1-00557, Madrid, Spain, Jun 2005.

[2] J. Li, X. Lu, J. Li, Y. Cai, and G. Zeng, "Prediction method and field experiment of casing damage in fault block X of Daqing oilfield," Acta Petrol Sinica, vol. 29, no. 4, pp. 625-628, 2008.

[3] C. Hu, J. Gao, and Y. Liu, "The impact of casing damage critical condition on marker bed with differential internal and external pressure in Daqing oilfield," Advances in Petroleum Exploration and Development, vol. 11, no. 1, pp. 42-44, 2016.

[4] Y. H. Zhao, H. Q. Jiang, H. Q. Li et al., "Research on predictions of casing damage based on machine learning," Journal of China University of Petroleum, vol. 44, no. 4, pp. 57-67, 2020.

[5] S. Na, "Slip mechanism of fault due to pressure difference and analysis of casing damage," Oil and Gas Field Surface Engineering, vol. 29, no. 5, pp. 23-25, 2010.

[6] J. Chen, Q. $\mathrm{Hu}$, and W. Wu, "Identification method for high-risk position of casing damage in the surface wellbore of a mining subsidence area based on laminate theory," Disaster Advances, vol. 6, pp. 139-148, 2013.

[7] L. Gao, L. Qiao, Z. Liu, Z. Zhuang, and H. Yang, "Numerical modeling and cementing countermeasure analysis of casing shear damage in shale reservoir," China Petroleum Machinery, vol. 44, no. 10, pp. 6-16, 2016.

[8] S. Q. Yang, P. F. Yin, and Y. H. Huang, "Experiment and discrete element modelling on strength, deformation and failure behaviour of shale under Brazilian compression," Rock Mechanics and Rock Engineering, vol. 52, no. 11, pp. 43394359, 2019.

[9] Z. Lian, G. Liu, B. Tang, F. Dong, and Y. Li, "Finite element analysis of casing damage in plastic flow formation," Natural Gas Industry, vol. 22, no. 6, pp. 55-62, 2002.

[10] H. Chen, N. Ge, and Q. Zhu, "Finite element modeling and mechanism analysis of casing damage in oil wells under liquid-solid interaction," Journal of Computational and Theoretical Nanoscience, vol. 19, no. 6, pp. 1701-1704, 2013.

[11] C. Hu, C. Ai, F. Tao, F. Wang, and M. Yan, "Optimization of well completion method and casing design parameters to delay casing impairment caused by formation slippage," in SPE/IADC Middle East Drilling Technology Conference \& Exhibition, Abu Dhabi, UAE, 2016.

[12] W. Tao, Y. Shenglai, Z. Weihong et al., "Law and countermeasures for the casing damage of oil production wells and water injection wells in Tarim oilfield," Petroleum Exploration and Development, vol. 38, no. 3, pp. 352-361, 2011.

[13] E. Engin and O. Cam, "Mechanism analysis of casing damage induced by high pressure water injection in Daqing oilfield," Journal of Psychiatric and Mental Health Nursing, vol. 16, no. 5, pp. 462-472, 2010.

[14] Z. Kui, "Research and application of casing damage prevention and early warning system," Journal of Yangtze University (Nat Sci Edit), vol. 9, no. 5, pp. 119-122, 2012.

[15] Z. Liwei, F. Lihua, and C. Yulian, "Research and application on the casing damage repairing technology of the block in tertiary oil recovery," Science Technology and Engineering, vol. 14, no. 23, pp. 46-50, 2014.
[16] C. C. Liu, "Casing damage mechanism analysis and preventive measures for oilfield water injection wells," Petrochemical Technology, vol. 26, no. 5, pp. 59-66, 2019.

[17] S. Guisheng, Casing failure forecast and disposal countermeasure research, Daqing Petroleum Institute, 2008.

[18] F. L. Yin, The on-line monitoring technology for the casing outside pressure and the casing strain based on the fiber-optic sensing technology, Harbin Institute of Technology, 2010.

[19] Y. Gong, F. Q. Tang, and J. Zhang, "Research of model test of surface movement and deformation by mining coal in loess mountain area," Mine Surveying, vol. 3, pp. 9-11, 2013.

[20] Y. F. Zou and H. B. Chai, Similarity theory of mining subsidence and its application, Science Press, 2013.

[21] X. Hui, H. T. Fei, T. Sun, J. Lin, L. Ma, and J. Yang, "Research and application of intelligent casing damage prevention and control system in Daqing oilfield," in Proceedings of the International Field Exploration and Development Conference, pp. 3853-3858, Xi'an, China, 2020.

[22] Y. Li, D. Jia, Z. Rui, J. Peng, F. Chunkai, and J. Zhang, "Evaluation method of rock brittleness based on statistical constitutive relations for rock damage," Journal of Petroleum Science and Engineering, vol. 153, pp. 123-132, 2017.

[23] T. Wang, T. Zhang, P. G. Ranjith et al., "A new approach to the evaluation of rock mass rupture and brittleness under triaxial stress condition," Journal of Petroleum Science and Engineering, vol. 184, article 106482, 2020.

[24] M. Sheng, S. Tian, B. Zhang, and H. Ge, "Frequency analysis of multi-sources acoustic emission from high-velocity waterjet rock drilling and its indicator to drilling efficiency," International Journal of Rock Mechanics and Mining Sciences, vol. 115, pp. 137-144, 2019.

[25] Y. Xue, J. Liu, P. G. Ranjith, X. Liang, and S. Wang, "Investigation of the influence of gas fracturing on fracturing characteristics of coal mass and gas extraction efficiency based on a multi-physical field model," Journal of Petroleum Science and Engineering, vol. 206, article 109018, 2021. 